\section{ARTE RUPESTRE PALEOLÍTICO EN EL YACIMIENTO SOLUTRENSE DE LA CUEVA DE AMBROSIO (VÉLEZ-BLANCO, ALMERÍA)(1)}

PALAEOLITHIC ROCK ART IN THE SOLUTREAN SITE OF LA CUEVA DE AMBROSIO (VÉLEZ-BLANCO, ALMERÍA)

\author{
SERGIO RIPOLL LOPEZ (*) \\ FRANCISCO JAVIER MUÑOZ \\ SARA PÉREZ \\ MARTA MUÑ̃Z \\ FÉLIX CALLEJA \\ JUAN ANTONIO MARTOS \\ RAMON LOPEZ Y CARMEN AMAYA (**)
}

\section{RESUMEN}

En el yacimiento solutrense de La Cueva de Ambrosio se han encontrado durante las campañas de 1992 y 1994 un conjunto de representaciones artísticas parietales pintadas y grabadas del Paleolítico Superior. Entre

(*) Departamento de Prehistoria e Historia Antigua de la Facultad de Geografía e Historia de la Universidad Nacional de Educación a Distancia. Avda. Senda del Rey, s/n. 28071 Madrid. España.

(**) Colaboradores en el Proyecto de Investigación "La Cueva de Ambrosio (Vélez-Blanco Almería). Estudio cultural, reconstrucción paleoecológica y posición cronoestratigráfica del Pleistoceno Superior Final en la Andalucía Oriental".

El artículo fue remitido en su versión final el 10-XI-94.

(1) Queremos agradecer desde estas líneas, el apoyo incondicional que nos ha prestado en todo momento D. José Joaquín Martínez López, Alcalde-Presidente del Excelentísimo Ayuntamiento de Vélez-Blanco, que una vez superado el escepticismo inicial, comprendió la importancia del hallazgo. También queremos destacar a la Dra. Doña Cándida Martínez, Decana de la Facultad de Geografía e Historia de la Universidad de Granada, que movilizó a gran número de personalidades que debían conocer el descubrimiento; una mención especial, merece el Dr. D. E. Ripoll Perelló, mi padre, que sorprendido por la existencia de las representaciones, posteriormente no dudó en autentificarlas. Por último, quiero mencionar al resto del equipo de excavación que en todo momento contribuyeron con su esfuerzo y trabajo al desarrollo de esta investigación. los grabados del panel I, se ha descifrado una excelente silueta de caballo, una representación de ave, unos protomos de bóvido y de caballo, así como otros trazos todavía no interpretados. En la parte inferior del panel existen pinturas, poco visibles a causa de una colada calcítica y de momento no es posible interpretar ninguna representación figurativa. En el panel II se han identificado un espléndido caballo pintado en ocre rojo, otros dos caballos grabados, un protomos de caballo pintado en negro y gran cantidad de líneas incisas en trazo múltiple, así como otros restos pictóricos todavía por identificar.

La excepcionalidad del hallazgo reside en el hecho de poder interrelacionar perfectamente estas muestras de arte con los niveles arqueológicos claramente definidos desde el punto de vista cultural y cronoestratigráfico (ca. 16000 B.P. Solutrense Superior y Solutrense Superior Evolucionado) del mismo yacimiento.

\begin{abstract}
In the solutrean site of La Cueva de Ambrosio several engraved and painted figures dated on the Upper palaeolithic, have been found during the field works of 1992 and 1994. In the panel I we have identified an excellent repre-
\end{abstract}


sentation of a horse, a bird, one bovidae and another protome of a horse. Below this surface there are many red ochre wallpaintings covered by a calcitic path and for the time being we are unable to give any interpretation for it. In the second panel we have discovered one splendid red painted horse, two more engraved horses and a little head of one other black painted horse. There are many engraved lines and pictural rests that must be studied in the future.

The exceptionality of this discovery is that we can interrelate perfectly these rock art paintings with the archaeological levels clearly defined chronologically and culturally (ca. 16000 B.P., Upper Solutrean and Final Solutrean) from the same site.

Palabras clave: Arte rupestre. Solutrense final. Cronología. Sureste español.

Key words: Rock Art. Final Solutrean. Chronology. Spanish southeastern.

\section{INTRODUCCIÓN}

Durante la campaña de excavaciones sistemáticas del año 1992 en el yacimiento de La Cueva de Ambrosio (Vélez-Blanco, Almería) (Fig. 1), actividad autorizada por la Dirección de Bienes Culturales de la Junta de Andalucía, se produjo un hallazgo de singular importancia para la prehistoria nacional e internacional.

En esta estación, en la que llevamos trabajando desde hace algo más de 10 años, se ha encontrado una de las secuencias más completas e interesantes para el período Solutrense del Mediterráneo español. Según las investigaciones llevadas a cabo hasta ahora, parece que este abrigo no se trataría de un lugar de habitación permanente, sino más bien de un lugar al que se acudía en determinados momentos a renovar el utillaje lítico (Ripoll López et alii, 1988) y donde a pesar de la brevedad de sus estancias, constatado a través de la escasa potencia pero gran extensión de los hogares y la poca fauna susceptible de haber constituido un alimento, tuvieron tiempo para plasmar en sus paredes unas muestras de Arte Rupestre Parietal Paleolítico.

Hasta ahora la única representación figurativa que habíamos encontrado se localizaba sobre un compresor-retocador de caliza, de pequeño tamaño, con un protomos de caballı. Este hallazgo ya fue publicado en su momento (Cacho y Ripoll López, 1987; Ripoll Lópe» ! Cacho, 1990) y el encuadre cultural se vió dificultado por la circunstancia de haber sido hallado en el sedimento revuelto durante la campaña de excavaciones del año 1983. Sin embargo, sus características estilísticas nos permitieron incluirlo en un momento evolucionado del Solutrense, perfectamente documentado, por otra parte, en el nivel II del actual relleno del abrigo.

En La Cueva de Ambrosio el punto "0" de referencia o plano horizontal del yacimiento a partir del cual se miden todas la profundidades se encuentra situado sobre una zona más o menos lisa de la pared izquierda del abrigo. Por otra parte, teníamos noticias de que en este área quedaba algún resto de los niveles epipaleolíticos que por el momento no pensábamos investigar, preservándolos como reserva arqueológica. La superficie, a la que antes aludíamos, se sitúa a la derecha y por debajo de aquellos estratos y conservaba adheridos abundantes restos de sedimento de color amarillento que siempre habíamos encuadrado en el nivel estéril que separa los niveles superiores del Solutrense y los del Epipaleolítico. Además, al tratarse del umbral del abrigo, en algunas zonas se había depositado algún material de arrastre y una parte había cubierto la marca del punto "0", dificultando su visión, motivo por el que decidimos limpiarlo.

Al limpiar esta zona de la pared del abrigo, nos dimos cuenta de la idoneidad de la misma para contener representaciones incisas y continuamos esta tarea sin demasiadas esperanzas ya que han sido numerosos los investigadores que nos han precedido en el estudio de esta estación y no habían constatado representaciones parietales de ningún período (2). Pero para nuestra sorpresa, nos dimos cuenta de la existencia de algunas líneas grabadas que se extendían hacia el interior del abrigo. Finalmente, comprobamos que se trataba de un équido y de un ave.

(2) Tenemos que hacer una breve referencia al conjunto de bloques pintados con ocre rojo sin formar ninguna figura hallados por el Prof. E. Ripoll durante las campañas de los años 60 y que según sus diarios de excavación aparecían en el nivel inferior de la llamada trinchera de acceso al fondo del covacho. Durante nuestra campaña de limpieza del año 1994 , hemos localizado dicha trinchera y también gran cantidad de bloques pintados y grabados que están pendientes de estudio.

T. P., 51, n. $^{\circ} 2,1994$ 


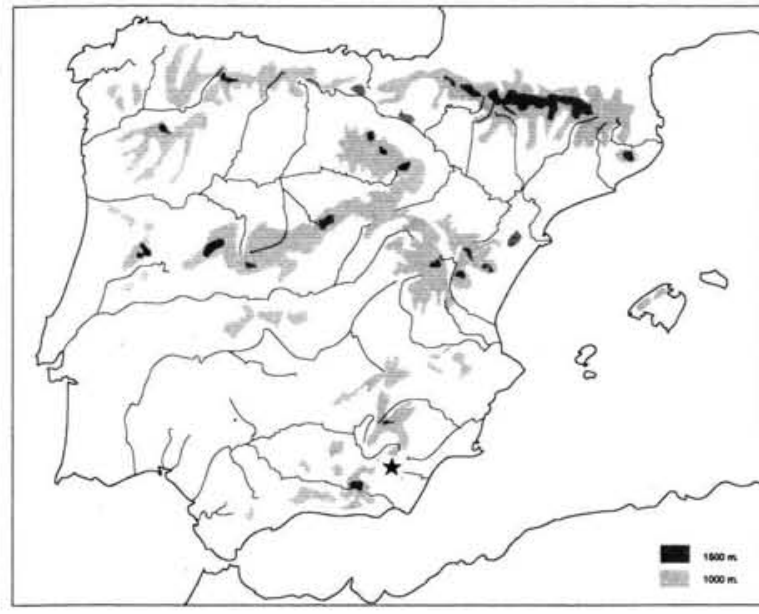

Fig. 1. Localización del yacimiento de La Cueva de Ambrosio (Vélez-Blanco Almería).

Este descubrimiento nos llevó a realizar una exhaustiva revisión de todas las paredes de la estación, con el fin de determinar si existían más representaciones. De esta forma en la parte inferior del panel grabado localizado en primer lugar, hallamos abundantes restos pictóricos y más hacia el interior del abrigo, al limpiar otra zona que contenía numerosas líneas incisas, también encontramos algunas figuras pintadas.

A raíz del descubrimiento en el año 1992, la Dirección General de Bienes Culturales de la Junta de Andalucía, junto con el director del Proyecto de Investigación, iniciaron una serie de gestiones con el fin de preservar el yacimiento y las representaciones. De esta forma en el año 1994, el organismo antes citado, autorizó una actuación puntual de limpieza y conservación de cara a valorar el yacimiento y poder contextualizar de una forma definitiva las representaciones paleolíticas. Esta labor se ha llevado a cabo de una forma exhaustiva por parte del equipo de investigación pero sin haber contado en absoluto con el apoyo institucional autonómico.

Con todo ello iniciamos una serie de trabajos sistemáticos, como es el calco a tamaño natural de las figuras sobre poliester transparente, que posteriormente se completó y contrastó con calcos realizados sobre televisión a través de la cámara de vídeo y una documentación fotográfica

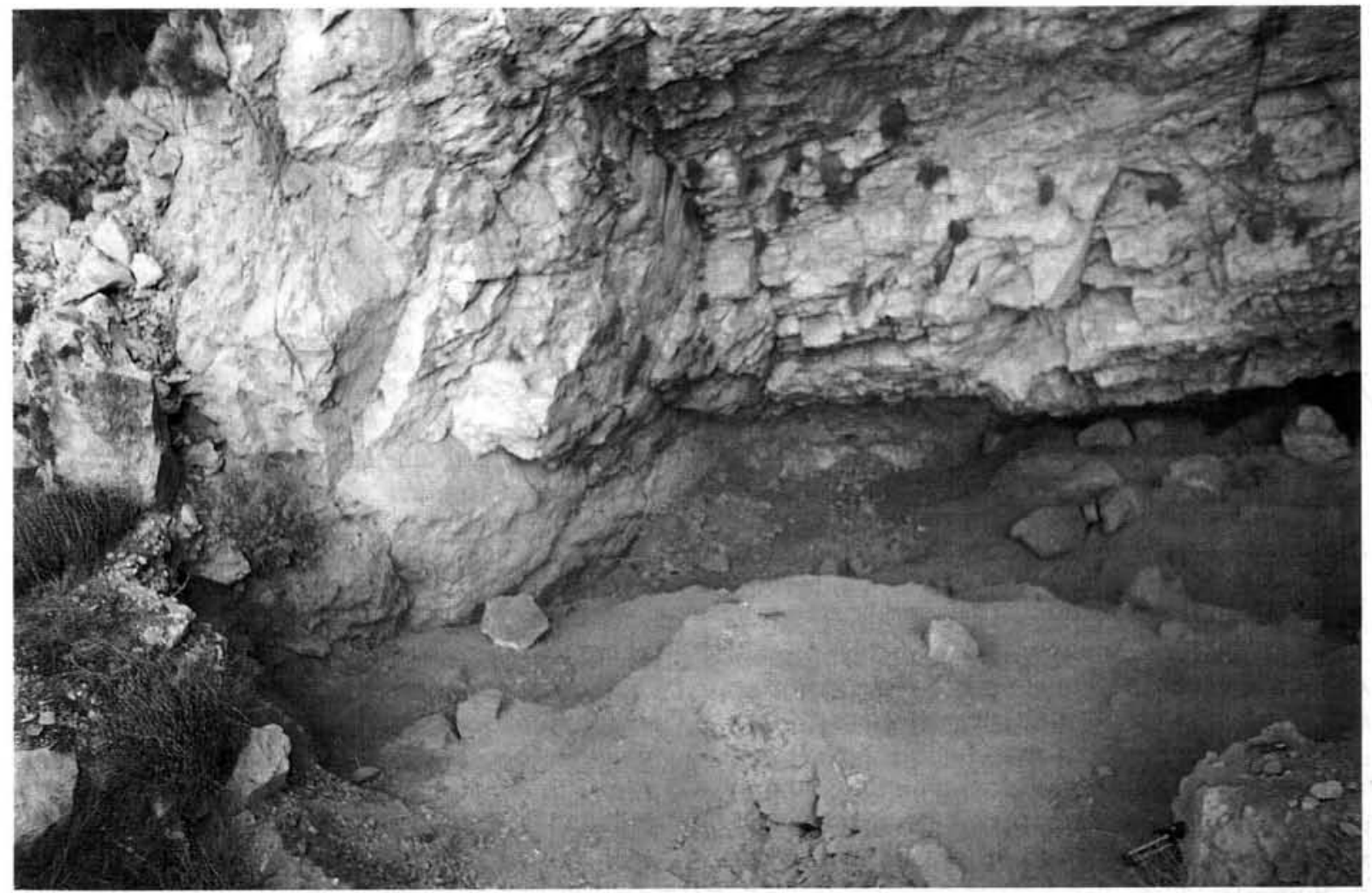

Lám. I. Vista general de la pared oeste del abrigo de la cueva de Ambrosio. En primer término se aprecia el panel I, más hacia el interior el II y en una posición prácticamente perpendicular, el panel III. 


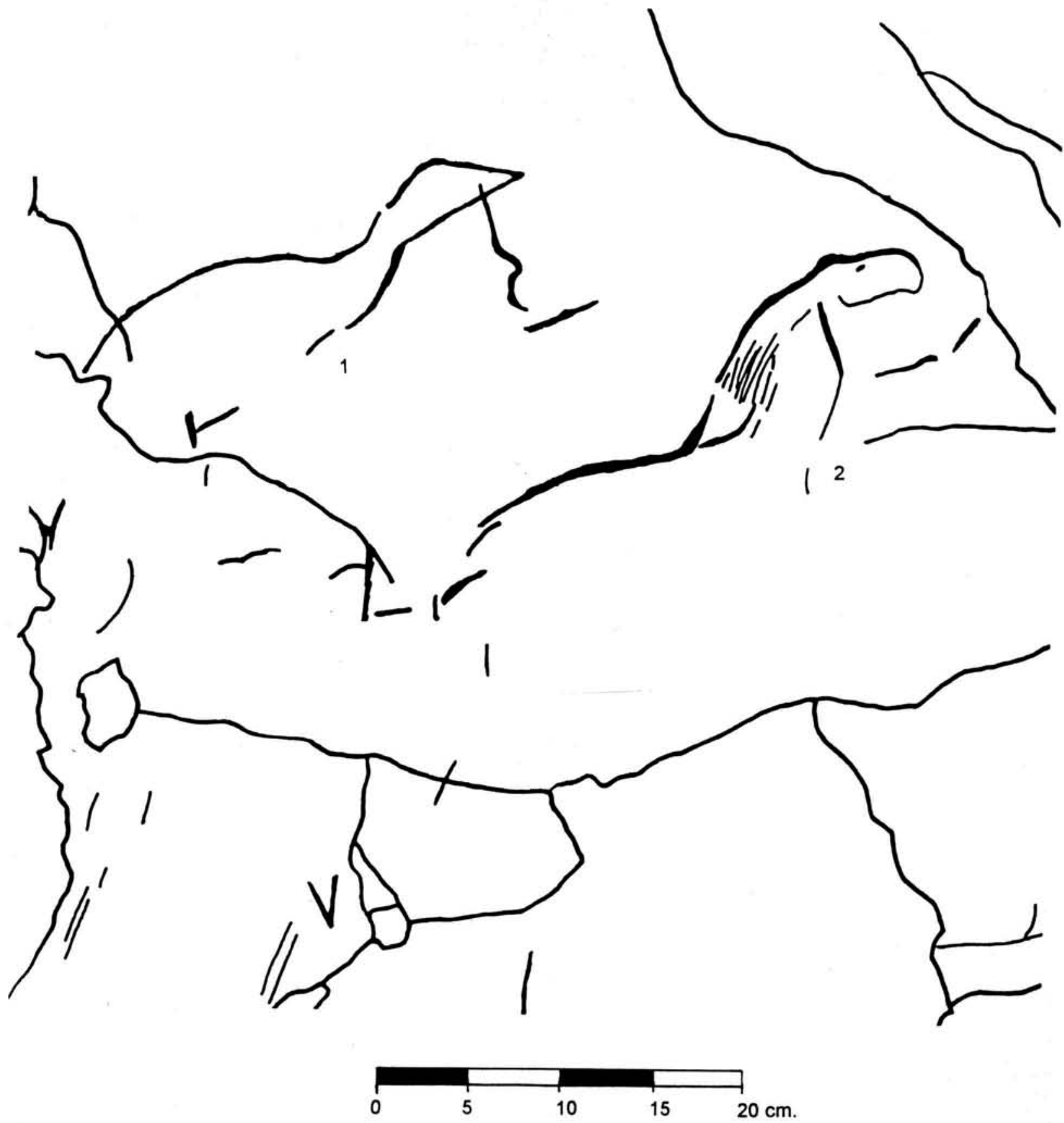

Fig. 2. Calco de la parte superior del panel I con las representaciones incisas de ave y équido descritas en el texto.

exhaustiva con diferentes tipos de luz, soporte y bajo diferentes condiciones atmosféricas.

Por el momento las manifestaciones de arte rupestre se concentran en tres paneles. El panel I se sitúa en el área exterior de la pared izquierda del abrigo; en la misma pared, a unos 4,50 metros del anterior, hacia el fondo de la cavidad y en una posición claramente inferior se encuentran los paneles II y III (Lam. I).
Todas las representaciones localizadas hasta el momento han sido realizadas sobre una superficie rocosa, más o menos lisa, limpia o ligeramente concrecionada de color blanquecino o beige (HUE 10YR-8/1) (3). La mayor parte de

(3) Especificación de color según las tablas Munsell (1954).

T. P., 51, n. ${ }^{\circ} 2,1994$ 
la colada calcítica que recubre la parte inferior del panel I se debe a una fase húmeda, claramente posterior a su ejecución.

\section{DESCRIPCIÓN DE LAS FIGURAS}

\section{PANEL I}

En el panel I hemos distinguido a su vez la parte superior y la inferior. En la de arriba, caracterizada por encontrarse exclusivamente representaciones incisas, hemos identificado un total de cinco figuras. Procederemos a describirlas de izquierda a derecha, en el sentido de las agujas del reloj, haciendo referencia, si hace al caso, a su color, según el código o tablas Munsell (1954).

1.- En primer lugar se aprecia una figura de ave $(30,4 \mathrm{~cm}$. de longitud por $18,1 \mathrm{~cm}$. de anchura) que mira hacia la derecha (Fig. 2, Lam. I), con un cuerpo fusiforme bien diferenciado y un pico que se prolonga a partir de la cabeza redondeada. La zona ventral esta bastante perdida y no se aprecian las patas que podrían proporcionarnos una identificación zootécnica más precisa. Esta figura esta realizada mediante un surco de 2-3 $\mathrm{mm}$. de anchura y tiene una profundidad que oscila entre los $2 \mathrm{~mm}$. de la parte posterior y $0,05 \mathrm{~mm}$. del pico. Por el tipo de pico podría tratarse de una anátida, pero por otra parte la silueta, en general, recuerda a una perdiz, especie de la que hemos encontrado restos en los niveles de ocupación (Sánchez Marco, 1988), y que sin duda integró la dieta alimenticia de estas grupos del Paleolítico Superior final.

2.- En este mismo panel I, hacia la derecha y a escasos centímetros de la anterior, se encuentra la primera figura incisa que descubrimos en La Cueva de Ambrosio. Se trata de una espléndida figura de équido $(29 \mathrm{~cm}$. de longitud por $16,2 \mathrm{~cm}$. de anchura) orientada hacia la derecha, cuya línea cérvico-dorsal forma casi un ángulo recto (Fig. 2, Lam. I). Esta última línea se prolonga desde la grupa hasta la crinera, donde se desdobla en un haz de trazos más finos, representando el despiece de la misma y tal vez el pelaje. La cabeza, de forma subcuadrangular, ligeramente inclinada hacia arriba, esta realizada aprovechando un resalte natural de la roca base. La oreja esta confeccionada mediante un simple ángulo en la parte superior y la línea de la cara se desarrolla hasta el morro, a partir de donde se aprovecha en mayor medida el resalte, incidiendo únicamente con un trazo más somero, en la parte del belfo que adquiere la característica convención en forma de "pico de pato". A continuación se perfila la quijada que asciende ligeramente hacia el interior de la cabeza en su parte final.

En la zona interior de la testuz se distingue con bastante claridad lo que hemos identificado como el ojo, realizado mediante un impacto piqueteado circular.

Escasamente relacionada con el resto de la figura se diferencia la línea del pecho. Parece que de forma intencional no se ha querido representar la parte inferior del cuerpo, es decir las extremidades y la línea ventral. La línea cérvico dorsal esta realizada mediante un surco bastante amplio (2-3 $\mathrm{mm}$.) y profundo, de sección en $\mathrm{U}$, frente al despiece de la crinera, cuyos trazos son muy finos y someros, sin poder llegar a medir su profundidad. La incisión de la quijada es casi inexistente observándose, sin embargo, algunas estrías que permiten completar la figura junto con los resaltes naturales de la roca.

Se trata de un animal con unas proporciones equilibradas en el que se pone de manifiesto su acusado realismo, aunque no esta exento de tendencias estilizantes. El contorno de esta representación muestra un équido asustado o alarmado con la parte anterior de su cuerpo en posición erguida como para distinguir la causa que lo ha alertado, ya fuera sonido u olor.

3.- En la parte inferior derecha de este panel I hemos distinguido otras figuras. En primer lugar hay que señalar una línea cérvico-dorsal y la oreja de un équido $(17,5 \mathrm{~cm}$. de longitud por $10,4 \mathrm{~cm}$. de anchura) que mira hacia la derecha. El trazo es ancho y profundo, alcanzando los 2 $\mathrm{mm}$. de espesor y de sección en U, pero al encontrarse sobre una pequeña inflexión de la roca, que cambia de dirección, no se ha conservado el resto de la figuración.

4.- También bastante incompleto, pero más identificable, es un protomos de bóvido $(5,8 \mathrm{~cm}$. de longitud por $3,5 \mathrm{~cm}$. de anchura) orientado hacia la izquierda. Se diferencia bien el cuerno curvado hacia atrás, en perspectiva simple y la cabeza ligeramente subtriangular, y a continuación el inicio de la línea dorsal, así como la del pecho. El trazo es bastante profundo y amplio en todo el contorno $(2 \mathrm{~mm}$.) con una sección en $\mathrm{U}$, salvo en el cuerno que es más tenue y de sección en V. 


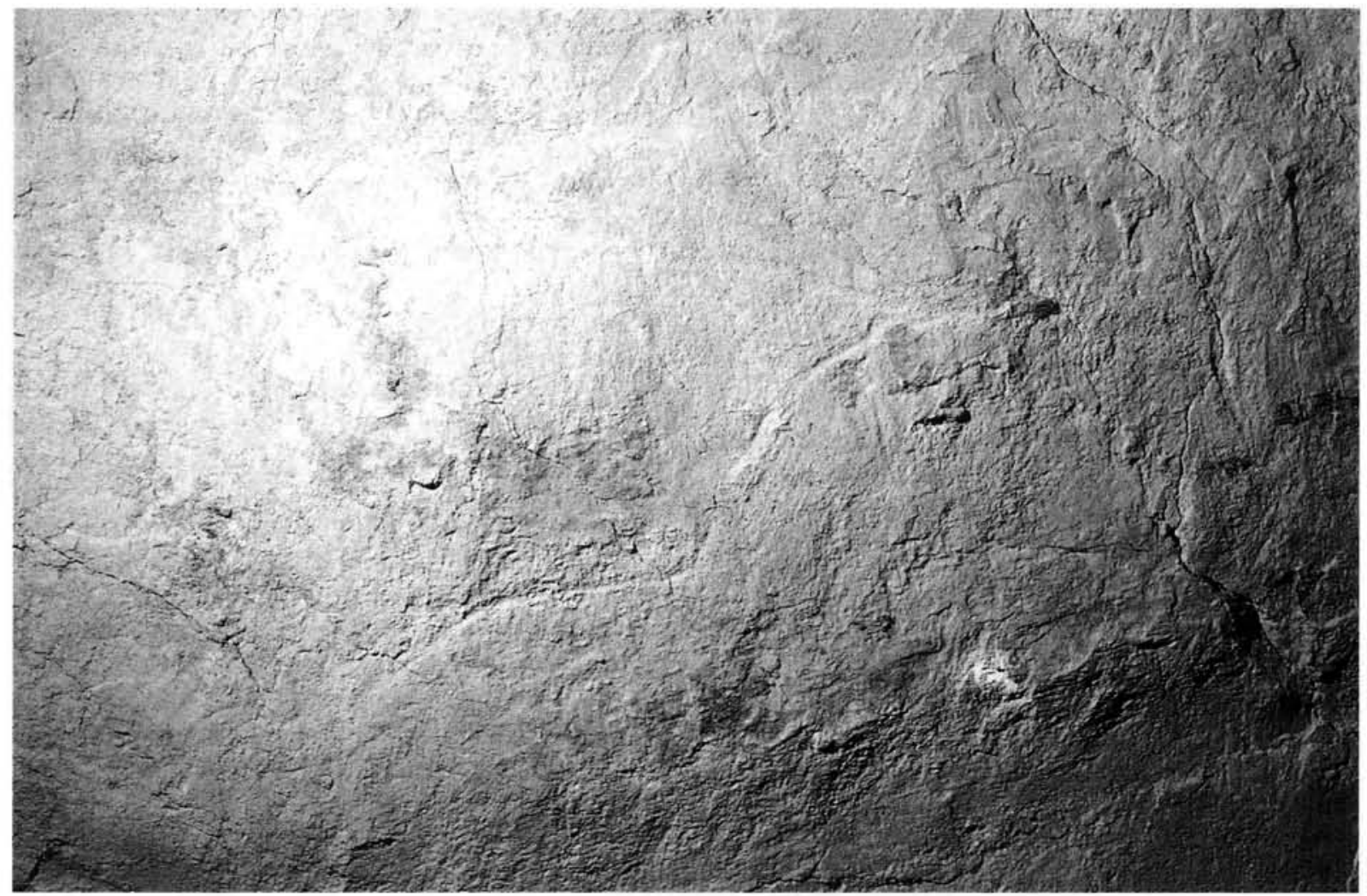

Lám. II. Fotografía que coincide casi totalmente con el calco de la figura 3 con la parte anterior del ave consignada con el número 1 y el caballo grabado número 2 .

Existen otros grabados de las mismas características por toda esta extensa superficie, pero de momento, a falta de un análisis más pormenorizado, no hemos conseguido identificar otras representaciones naturalistas. Además se adivinan otras líneas sumamente someras -como si hubiesen sido raspadas- sobre esta misma superficie que tendremos que investigar en futuras campañas de documentación.

En la parte inferior del panel I, distante unos $40 \mathrm{~cm}$. del superior, por debajo de la inflexión antes mencionada, hemos hallado unos restos pictóricos en ocre rojo muy desvaído (HUE 10R-3/6). Todos ellos se localizan por debajo de una espesa colada calcítica, que los hace poco visibles y que no hemos querido retirar, si no es con la colaboración de un especialista, ya que el pigmento corre peligro de desaparecer. Entre estas figuras se distingue una silueta subcuadrangular (HUE 10R-4/8) que tal vez y con carácter provisional, podría clasificarse como un típico signo paleolítico (¿tectiforme?). Más hacia la derecha, y en una posición sensiblemente inferior, existe otro trazo también en ocre anaranjado (HUE 2.5YR-4/8), bastante evidente que podría corresponder a los cuartos traseros e inicio de la línea ventral de un cuadrúpedo. Pero, como ya hemos explicado, hasta que no se limpie la calcita de este panel, preferimos no aventurar hipótesis. Sin duda su limpieza nos proporcionará un amplio repertorio de figuras que engrosarán el inventario de este inusual descubrimiento.

\section{PANEL II}

El segundo panel, situado más hacia el interior del abrigo, se encontraba oculto por una espesa capa de sedimento revuelto y bloques procedentes de excavaciones incontroladas. Empezamos a retirarla con mucha precaución, ya que se adivinaba una gran superficie lisa e inmediatamente distinguimos un conjunto de trazos grabados de enorme complejidad, así como dos pequeñas manchas de ocre rojo en la parte inferior (Fig. 3). 


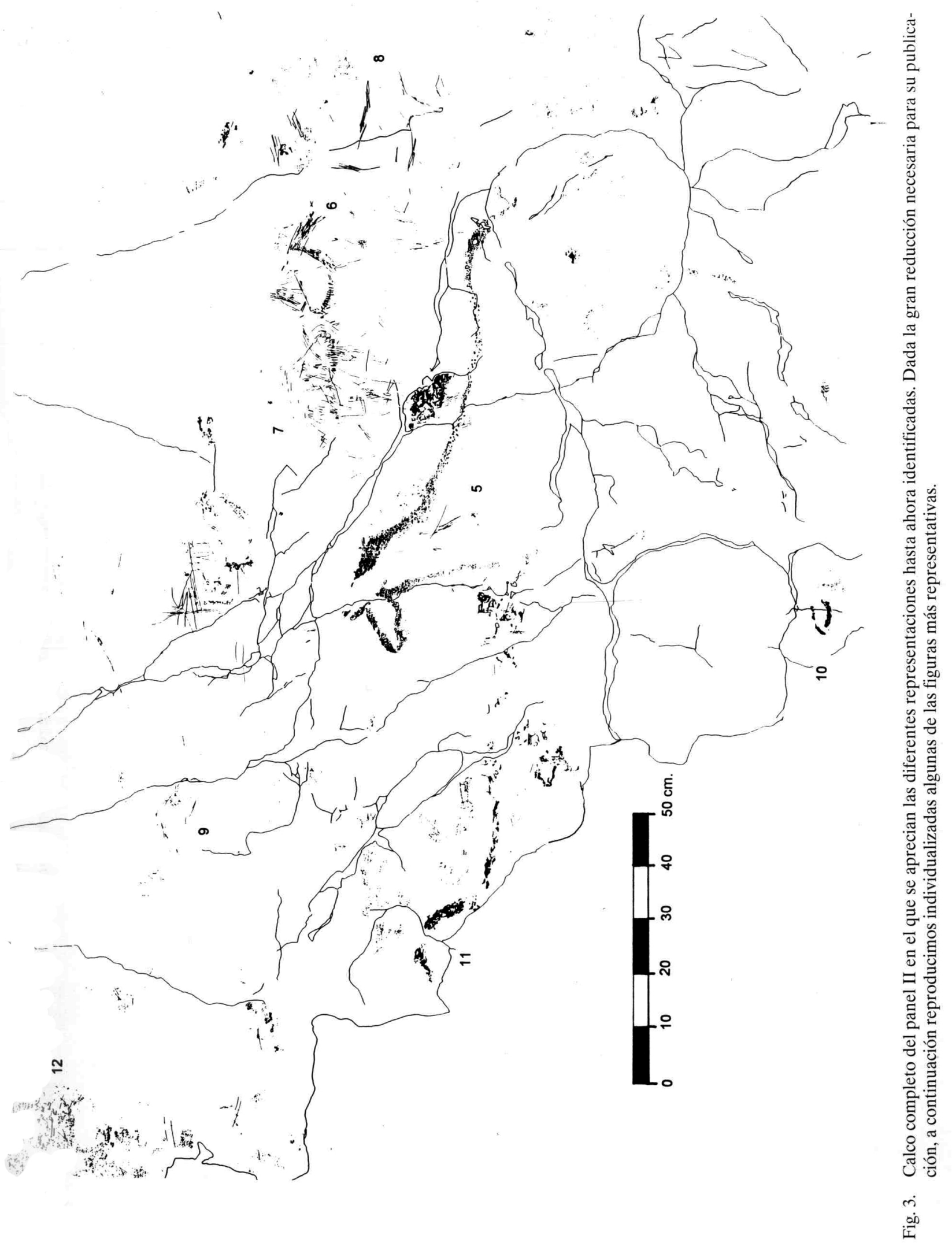

T. P., 51, n. ${ }^{\circ} 2,1994$ 


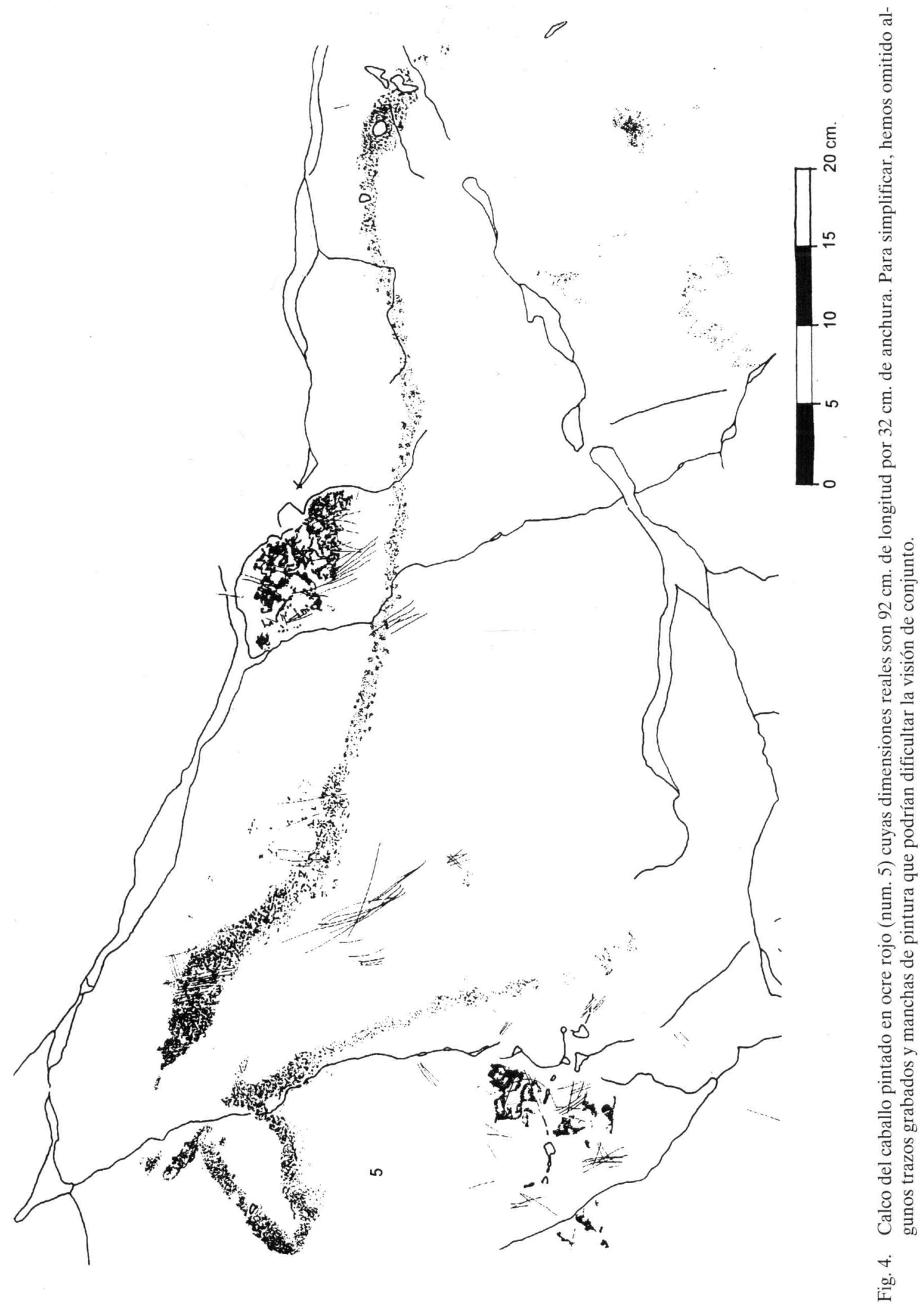

T. P., 51, n. ${ }^{\circ} 2,1994$ 
La superficie del panel II es mucho más regular, de un color gris marronáceo (HUE 7.5 YR-6/4), en todo caso más oscura que la del panel I. Esta surcada por finas grietas que no restan uniformidad al conjunto de figuras. En el momento de su descubrimiento aparecieron pequeñas escamas de concreción caliza, sobre todo en la zona ocupada por el équido grabado (núm. 8).

De una manera totalmente accidental, tuvo lugar el descubrimiento de la figura más espectacular de toda la campaña: un espléndido caballo pintado en color ocre rojo, en una zona en la que ya habíamos empezado a trabajar. Sorprende por su buen estado de conservación general y sobre todo contrasta con las otras figuras descritas en el panel I por su claridad y notables dimensiones.

5.- Esta magnífica representación de équido $(92 \mathrm{~cm}$. de longitud por $37 \mathrm{~cm}$. de anchura desde las orejas hasta la línea del pecho y 53 $\mathrm{cm}$. de anchura desde la grupa hasta el final de la pata trasera), orientado hacia la izquierda, esta pintado en ocre rojo (HUE 10R-3/3) (Fig.
4, Lam. III). Toda la figura esta silueteada mediante un trazo grueso que varía entre 1 y 2 centímetros de espesor en casi todo el contorno salvo la cabeza en donde oscila entre 1 y $1,5 \mathrm{~cm}$. Se conserva perfectamente la parte superior de la figuración, es decir la cabeza, línea del pecho, la crinera ligeramente dañada y toda la línea cérvico dorsal hasta la grupa. En un principio pensamos que el caballo tenía el inicio de la cola, tal como representamos en los primeros calcos publicados (Ripoll López et alii, 1992; Ripoll López, 1994). En la actualidad un estudio más detallado de la figura nos ha permitido apreciar que se trata de una mayor acumulación de pigmento en la zona de la grupa. Al haber excavado durante la campaña de 1994 en esta zona, debajo del panel II, se ha mejorado notablemente la visualización de esta figura en la que se distinguen pequeños restos de pigmento que conforman lo que sería el muslo y la babilla de la pata trasera, por otra parte muy desvaída. En la cabeza se aprecia una de las orejas y un fragmento de la otra en la parte superior hacia adelante. Así mismo la quijada con su inflexión,

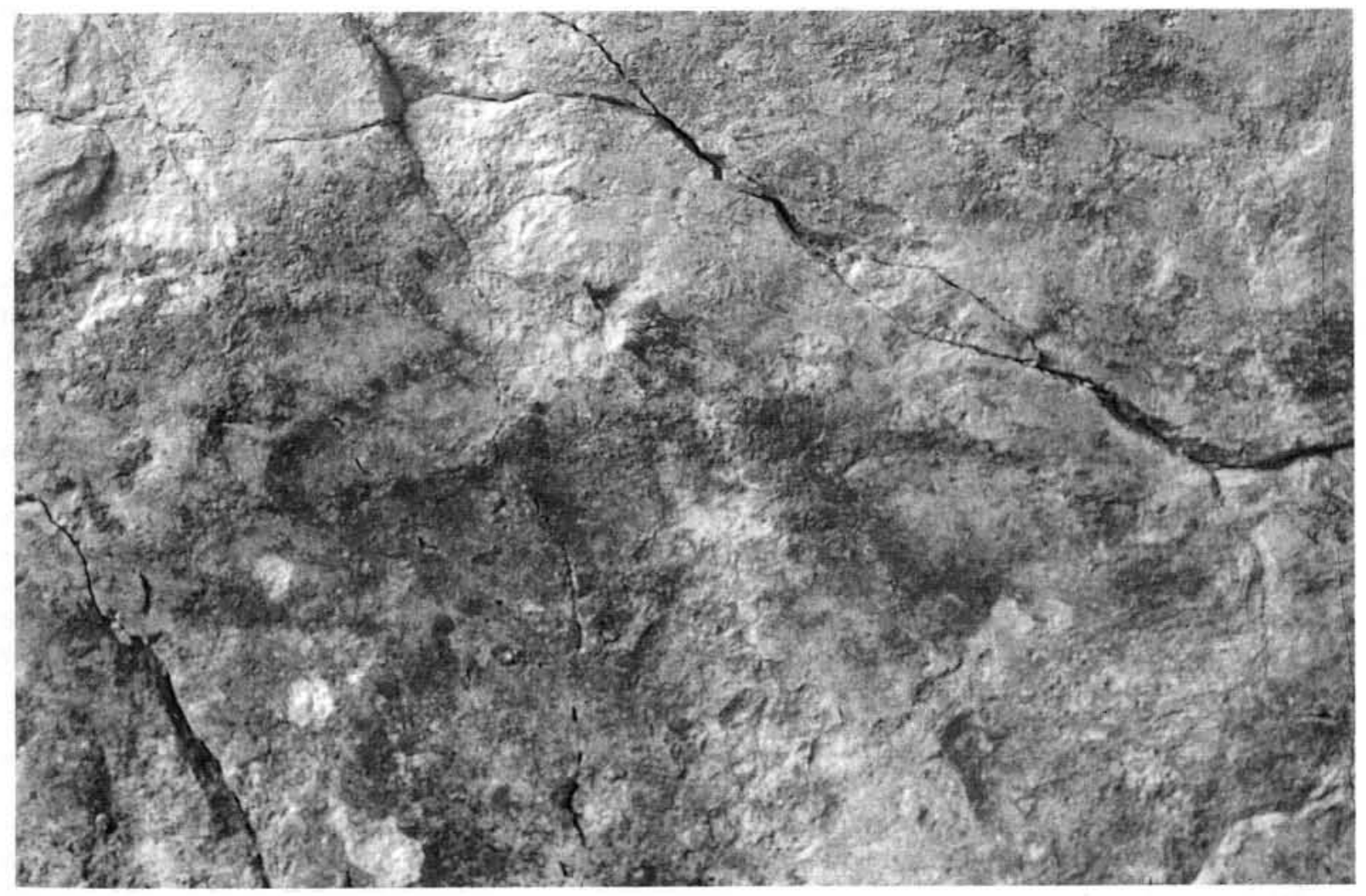

Lám. III. Protomos del espléndido caballo pintado en ocre rojo número 5, situado en el centro del panel II. El resto de las representaciones se sitúan a su alrededor. 
que sin embargo, no llega a adquirir totalmente la característica forma de "pico de pato". La línea se prolonga hasta unirse al trazo del pecho, penetrando de forma más o menos curva hacia el interior de la cabeza para marcar la mandíbula. Es en esta zona, precisamente, junto con la crinera donde se aprecia una mayor concentración de colorante, e incluso se podría pensar que al pintor, al aplicar la pintura, se le corrió un poco, produciendo una ligera mancha de pigmento, sin que por el momento podamos pensar que se trata de un lavado posterior. La crinera parte de la misma altura que la oreja y, a pesar de existir un efracto natural de la roca, su continuidad hacia el dorso se hace patente por unos puntos pictóricos en la parte superior. Una observación de detalle de esta zona nos permite comprobar la técnica de realización de la misma. En un primer momento se silueteó con una línea exterior, rellenándose posteriormente mediante líneas de grosor variable hasta cubrir todo el espacio interior. Es en esta zona, donde la pintura esta más "fresca", mejor conservada y delimitada, ya que la línea cérvico-dorsal se difumina desde la crinera hacia la grupa. La línea del pecho se une a la pata anterior por un trazo sinuoso bastante desvaído y tenue, aunque visible en una observación ocular muy próxima. Nada indica que la parte posterior de la pata delantera, la línea del vientre y los cuartos traseros fueran jamás pintados, aunque no descartamos su existencia después de una limpieza exhaustiva y la aplicación de algunos métodos fotográficos especializados (infrarrojos, falso color, etc.).

Es comunmente conocido que la viveza del color, sobre todo de los óxidos de hierro (hematites y ocre) depende del grado de humedad de las paredes. La frescura de la pintura del équido del panel II de La Cueva de Ambrosio estaba en su grado optimo, gracias a una hidrometría favorable. En esta zona -la más baja del abrigocuando llueve, se produce un goteo continuado. La existencia por otra parte de un nivel de arenas estériles depositado encima de un nivel de ocupación, que actúa como una capa impermeable dado el alto contenido de materia orgánica, provoca que aquellas arenas conserven mucho la humedad, lo que sin duda ha favorecido el excelente estado de conservación de esta figura.

6.- En el ángulo superior derecho de este panel II se encuentra una zona particularmente densa en trazos incisos en la que hemos identificado dos protomos grabados de caballos enfrentados. El de la derecha, esta de momento mucho más completo que el de la izquierda, ya que no se ha limpiado del todo la colada calcítica que lo cubría y que, en principio, definimos como simples trazos en $\mathrm{X}$ e $\mathrm{Y}$ (Ripoll López et alii, 1992). La figura que nos ocupa con unas medidas de $62 \mathrm{~cm}$ de longitud y $28 \mathrm{~cm}$. de anchura, es de una excelente factura y nos presenta un caballo robusto con una quijada "barbuda" (Fig. 5, Lam. IV). La cabeza de forma subtriangular es muy característica de este tipo de representaciones. La testuz esta realizada mediante un único trazo de sección en $\mathrm{V}$ y tiene una profundidad de 1 a 1,5 $\mathrm{mm}$.; se distingue una pequeña rectificación en la zona media debida sin duda a una mínima execrencia de la roca. En el morro se puede ver claramente el ollar situado en la parte superior hecho con un trazo casi circular en cuyo interior hay otros breves surcos. El morro en sí es rectilíneo siguiendo con un trazo único y en el inicio de la quijada pierde su continuidad siendo interrumpido por un conjunto de 16 trazos más o menos profundos que representan las barbas. En la inflexión posterior de la mandíbula inferior se vuelve al trazo continuo, aunque en este caso la característica es que es múltiple como si el artista hubiese querido resaltar la fortaleza del animal; la quijada se prolonga hasta la parte superior del cuello uniéndose prácticamente con la línea de la crinera. No se aprecia el ojo, aunque en el interior de la cabeza existen numerosos trazos que, a falta de un estudio más profundo, creemos que se trata de despieces de la figura. En la parte superior, las dos orejas se proyectan hacia adelante en sendos trazos dobles, que adquieren una posición semejante a las del caballo pintado (núm. 5). La crinera se inicia en las orejas desdoblándose en dos trazos más o menos paralelos que se separan a medida que nos alejamos de la cabeza. La línea cérvico dorsal se prolonga hasta la grupa y por ahora no hemos podido identificar las extremidades, por su parte la línea del pecho, en trazo múltiple, se alarga hasta el encuentro o inicio de las patas delanteras.

7.- El otro caballo grabado $(22 \mathrm{~cm}$. de longitud por $23 \mathrm{~cm}$. de anchura) orientado hacia la derecha, de factura muy similar al que acabamos de describir, aunque quizás su aspecto en conjunto sea menos completo que el ante- 


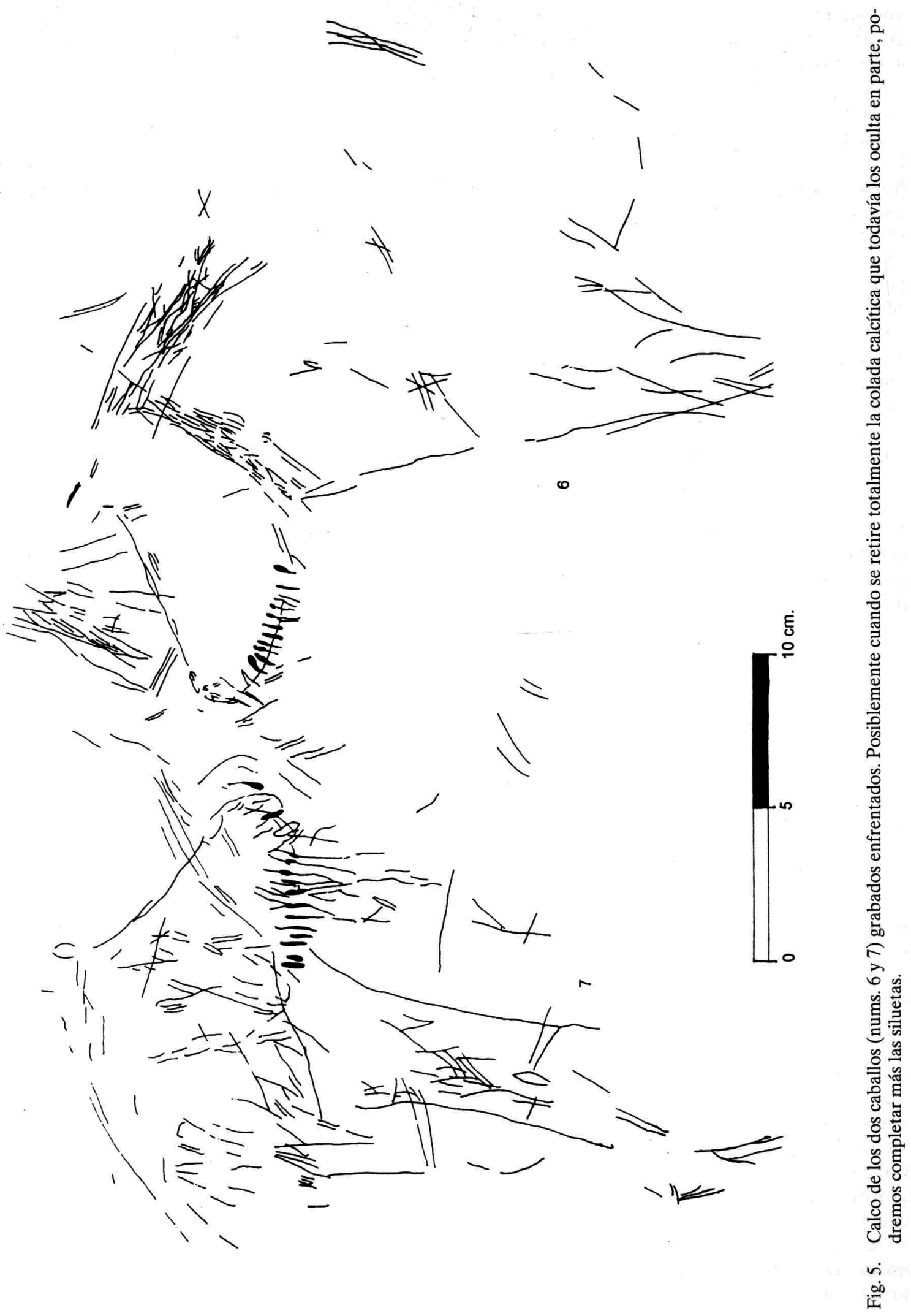

T. P., 51, n. ${ }^{\circ} 2,1994$ 


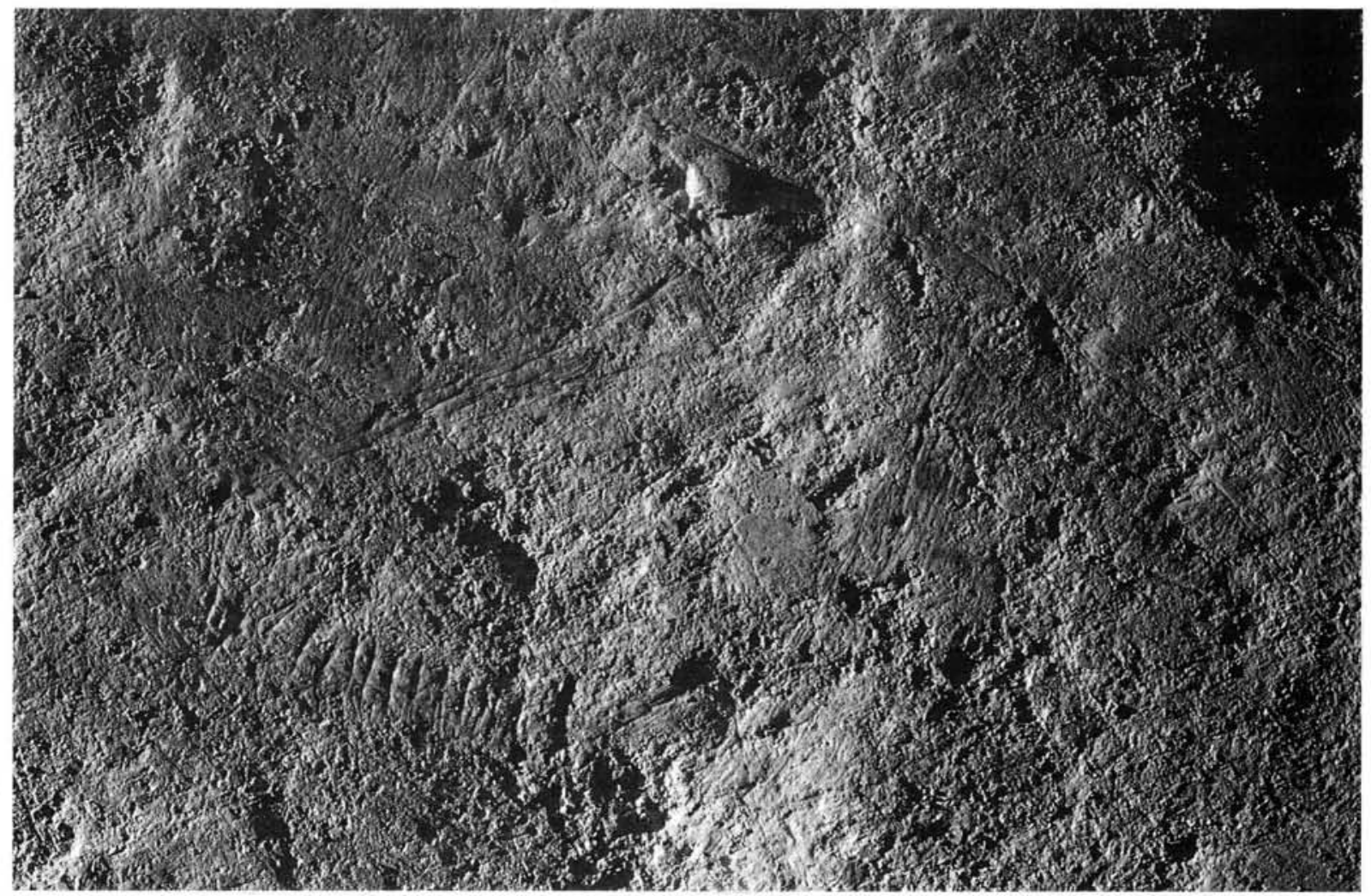

Lám. IV. Detalle de la cabeza de uno de los caballos enfrentados (num. 6) con las "barbas" que como ya hemos explicado en el texto, en un primer momento los consideramos simples trazos en X e Y.

rior pero ello es debido a la colada calcítica antes mencionada. La cabeza posee una testuz más pronunciada con un trazo simple bien marcado que se prolonga hasta el morro donde posee una inflexión. La zona del ollar se ha perdido por un mínimo efracto de la roca base y los trazos de la barba, en un número de 13 , son algo más profundos en la zona de la mandíbula y a medida que se alejan de ella se hacen más finos y tenues. La quijada es menos pronunciada y penetra en un ángulo casi recto en la cabeza. En la parte alta únicamente se aprecia una oreja claramente elíptica en contraposición al resto de las representadas en las otras figuras y el inicio de la crinera no se distingue, aunque si podemos seguirla en la zona del lomo, punto éste donde de momento se pierde la representación. La línea del pecho, realizada mediante un único surco, se prolonga también hasta el encuentro. En el interior de esta figuración se identifican numerosas incisiones que se encuentran ocultas en parte por costras calcíticas y que por el momento no podemos descifrar.
8.- A la derecha de este conjunto de trazos hemos podido identificar otra representación de caballo, realizada también con la técnica de grabado lineal muy fino. Posee unas dimensiones de $28,7 \mathrm{~cm}$. de largo por $15,2 \mathrm{~cm}$. de ancho, y creemos que esta orientado hacia la derecha, ya que no se aprecia claramente ni los cuartos traseros ni la zona de la cabeza, sin embargo se distingue una incipiente línea del pecho. La incisión es muy somera y posee las mismas características que las descritas anteriormente. La línea ventral, en trazo múltiple, se alarga hacia la izquierda, partiendo desde lo que hemos considerado como la pata delantera que se ha resuelto mediante sendos trazos subparalelos, cerrándose la parte correspondiente a la pezuña con un surco perpendicular.

9.- A la izquierda de aquellos dos magníficos caballos, bajo la costra calcítica que también los recubría, hemos identificado una cabeza de caballo (15 cm. de longitud y $12 \mathrm{~cm}$. de anchura), orientada hacia la derecha que, si bien sigue la misma estructura morfológica que los descritos anteriormente, presenta una realización mucho 


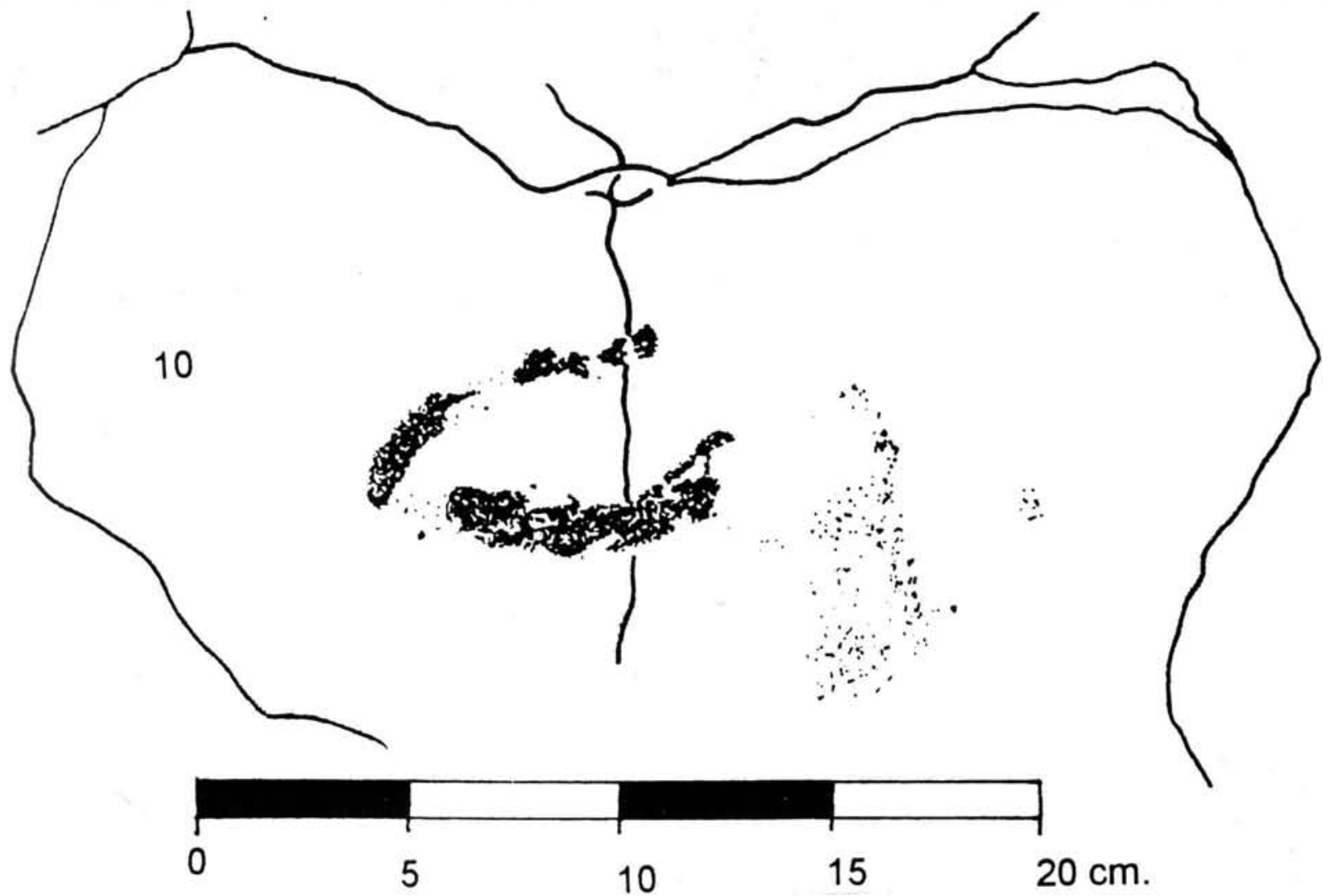

Fig. 6. Cabeza de caballo (num. 10) situada en la parte inferior del panel II y que en el momento de su descubrimiento se encontraba oculta por una capa de sedimento intacto compuesto a base de limos fluviales amarillos, encuadrados en la base del nivel III.

más tosca sin duda condicionada por las numerosas fisuras de la roca soporte.

10.- En la parte inferior del panel II, cubierto claramente por restos de limos fluviales de color amarillo encontramos en la campaña de 1994 un pequeño protomos de caballo (11 $\mathrm{cm}$. de longitud y $7 \mathrm{~cm}$. de anchura) pintado en negro y rojo (Fig. 6, Lam. V). A simple vista se trata de una silueta elíptica, aunque un examen en detalle de la misma nos muestra la línea de la testuz, el morro bastante desvaído y una quijada muy marcada con su correspondiente inflexión hacia el interior de la cabeza. Lo excepcional de esta figura es que la línea del pecho esta realizada en ocre rojo-anaranjado (HUE 2.5YR-4/8) de escaso recorrido que junto con la cabeza negra sería un indicio de bicromía. El artista supo expresar con tres líneas una figura que claramente es un caballo.

11.- En la parte izquierda de este panel II, junto con la inferior, es donde más novedades se han producido durante la campaña de 1994. En el ángulo inferior izquierdo se distingue una amplia mancha de color negro que provisionalmente consideramos como otro équido orientado hacia la izquierda $(38 \mathrm{~cm}$. de longitud y $10,5 \mathrm{~cm}$. de anchura). Se trata de dos trazos más o menos curvos con una anchura que oscila entre 1 y $2,5 \mathrm{~cm}$. que configuran con bastante claridad la crinera y línea cérvico-dorsal de un caballo. El color, sin duda realizado con carbón vegetal, es muy intenso en algunos puntos (HUE 10YR 2/1), mientras que en el arranque de la cabeza se difumina poco a poco (HUE 10YR 6/1) hasta desaparecer.

De esta representación se ha tomado una muestra que esta siendo analizada por la Dra. Hélène Valladas mediante el acelerador de partículas en el Centre des Faibles Radioactivités de Gif-Sur-Yvette (Francia), para obtener una datación radiocarbónica que nos permita encuadrar con una mayor precisión cronológica las representaciones parietales.

12.- Por último, en el ángulo superior izquierdo, después de haber retirado una considerable extensión de costra calcítica, hemos ha- 


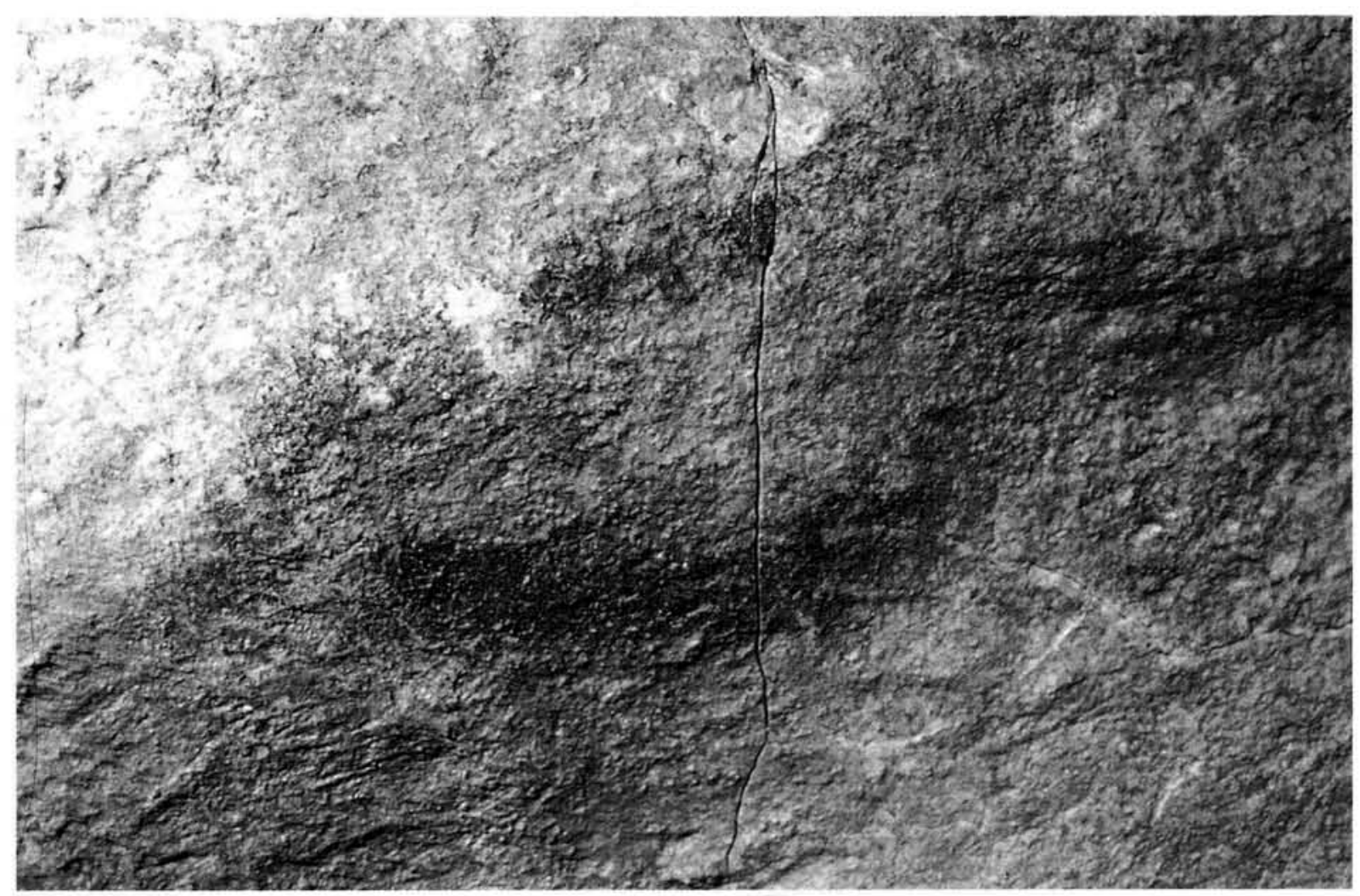

Lám. V. La simplicidad de líneas, no es un obstáculo para identificar una pequeña cabeza de caballo pintada en negro, mientras que la línea del pecho es en ocre rojizo.

llado una pequeña cabeza de caballo $(6,3 \mathrm{~cm}$. de longitud por 7,6 de anchura) orientado hacia la izquierda, realizado mediante un trazo sumamente fino y somero y que dado lo fragmentario de esta representación completaremos su descripción cuando se posea una mayor superficie al descubierto.

Por toda la superficie del panel II hemos descubierto numerosas manchas de ocre. Algunos restos situados a ambos lados y por encima del caballo pintado, son por el momento completamente indescifrables y no merecen más comentarios que señalar su presencia y tonalidad. Así, los que se encuentran a la izquierda del équido, es decir por delante de su cabeza, son de color marrón muy oscuro, casi negro (HUE $10 \mathrm{YR}-2 / 2$ ) y rojo muy intenso (HUE $10 \mathrm{R}-4 / 8$ ), mientras que los que se sitúan por detrás de la grupa son de un matiz ocre mas desvaído (HUE 10R-6/6).

Como ya hemos mencionado al inicio de la descripción del panel interior, apreciamos la existencia de algunas escamas de caliza, que al no estar situadas encima de manchas de colorante, pero sí sobre los caballos grabados y sobre el gran caballo pintado, procedimos a retirar algunas de ellas con un cuidado extremo, mediante una serie de útiles de precisión, apareciendo casi al completo estas representaciones.

Por último, en la parte superior de este panel, y por encima de la parte que se encontraba oculta por el sedimento, descubrimos otro conjunto de trazos grabados, estriados, que fueron los que nos indujeron:a iniciar la limpieza de esta zona. Estas incisiones tienen una mayor complejidad identificativa ya que infrapuesta a la concreción pero rellenando el surco de los grabados, se aprecian restos pictóricos de color ocre rojo muy claro (HUE 10R-6/6). Se trata de un conjunto de trazos organizados, largos y tenues, formando haces de líneas compactas, cuya dirección es variable. Este conjunto deberá ser analizado en profundidad después de su limpieza y restauración.

T. P.. 51, n. $^{\circ} 2,1994$ 


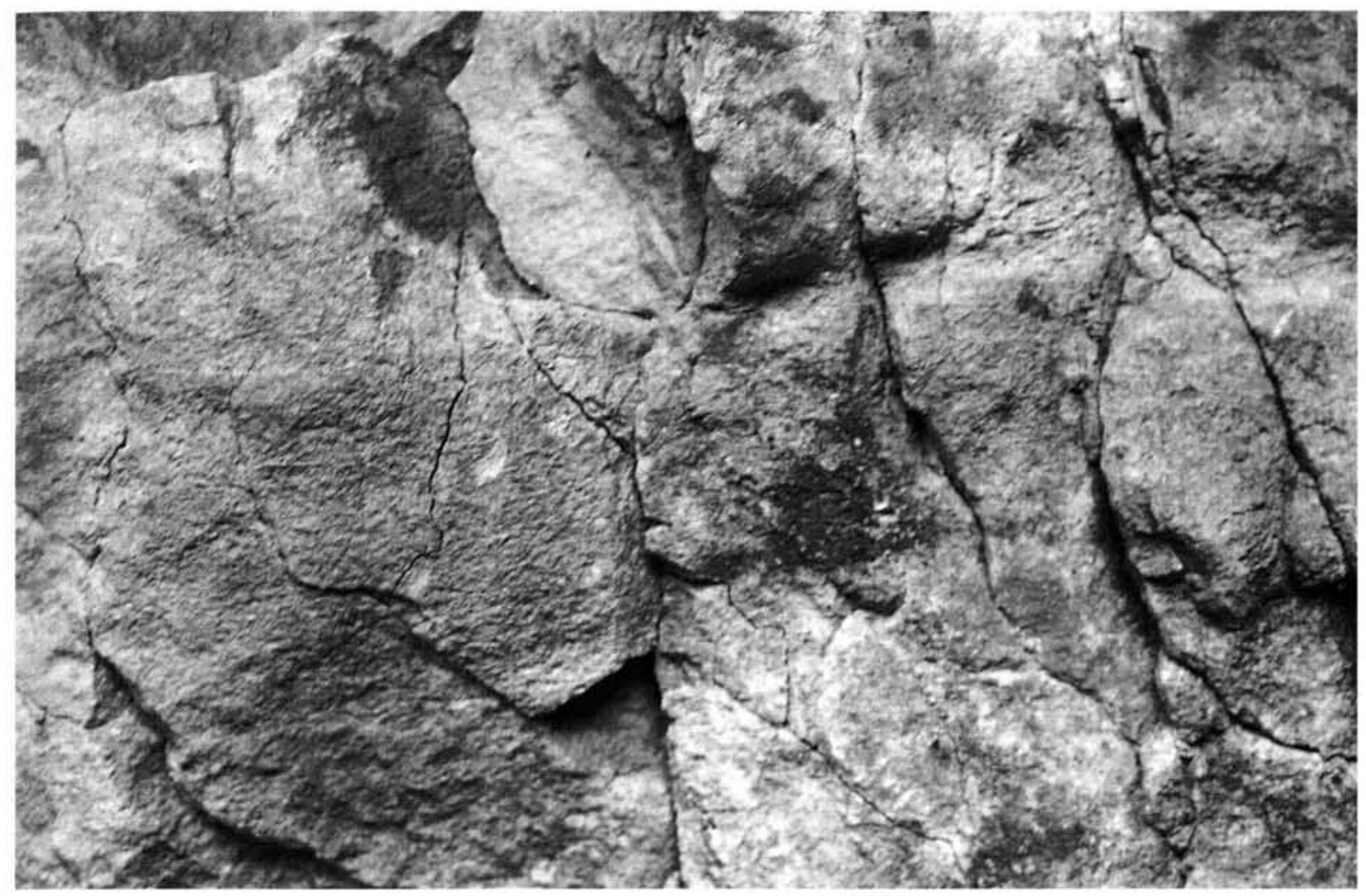

Lám. VI. Vista de conjunto del panel III donde se distinguen claramente las representaciones descritas con los números 14 y 15 .

\section{PANEL III}

Durante la campaña de limpieza del año 1994, al excavar frente al panel II que en su parte más profunda coincide de forma oblicua con el fondo del abrigo, localizamos un nuevo panel con representaciones pintadas. Sobre una superficie bastante alterada de color blanquecino (HUE 5YR 8/1) se encuentran tres conjuntos pictóricos de escasa representatividad dado que se encuentran muy desvaídos, pero que sin duda engrosan el inventario provisional de figuras paleolíticas de este yacimiento.

13.- Se trata, de izquierda a derecha de una puntuación elíptica en ocre rojo intenso (HUE 10R 3/4) con unas dimensiones de $9,8 \mathrm{~cm}$. de longitud por $7,5 \mathrm{~cm}$. de anchura. Se encuentra aislada en una superficie exenta de la pared y no tiene conexión con otras figuras.

14.- En el centro del panel III muy tenue, hemos distinguido otra mancha rojiza (HUE 2.5 YR $4 / 8)(15 \mathrm{~cm}$. de longitud por $14 \mathrm{~cm}$. de anchura) que aparece de forma inconexa con respecto al resto del conjunto
15.- Por último, en la zona de la derecha, se identifica una representación de mayor complejidad realizada en ocre rojo (HUE 10R 4/8) $(9,8$ $\mathrm{cm}$. de longitud por $21 \mathrm{~cm}$. de anchura) (Lam. VI), que se compone de una mancha muy desvaída a la izquierda, de cuya zona inferior parte un trazo horizontal de $2 \mathrm{~cm}$. de anchura que se prolonga a lo largo de $35 \mathrm{~cm}$. En el extremo de esta línea, de nuevo hacia arriba y con una coloración muy intensa (HUE 10R 4/6) hemos diferenciado un signo rectangular cuyos lados mayores son concavos. La interpretación es sumamente dificil ya que se encuentra en un estado muy fragmentario y no posee una forma concreta, ni tampoco se adapta a los contornos morfológicos de alguna especie animal.

\section{ENCUADRE CRONOLÓGICO}

Raras son las estaciones en las que se encuentran representaciones parietales cubiertas por niveles arqueológicos que permiten datarlos con precisión, y éste es el caso de La Cueva de 
Ambrosio. Si bien el panel I actualmente esta a la intemperie, en su momento estuvo cubierto por los niveles intactos que se encuentran a escasos centímetros hacia la izquierda y que fueron removidos por excavadores incontrolados así como por el natural desmoronamiento de los cortes de la trinchera abierta por E. Ripoll Perelló en los años 60 . Hasta el momento no hemos podido constatar el suelo de habitación desde el cual se debieron de realizar estas figuras, pero es de suponer que una próxima campaña rigurosa y sistemática de estudio de esta zona permitirá localizar los elementos propios que se debieron de utilizar para la factura. Con esta idea sometimos a la Dirección General de Bienes Culturales de la Junta de Andalucía un proyecto de excavación, consolidación y valoración, que como ya hemos comentado se ha desarrollado durante la campaña del año 1994. Sin embargo las labores de limpieza se prolongaron más de lo que inicialmente teníamos previsto y no se pudo llevar a cabo la excavación de los niveles arqueológicos intactos situados al pie de los paneles con figuraciones.

A continuación describiremos brevemente la secuencia estratigráfica establecida por nosotros en esta zona, que nos permite de una forma provisional encuadrar cada una de las representaciones en un horizonte cultural concreto.

En esta zona del abrigo, se encuentra, en primer lugar, un nivel de sedimento revuelto de escasa potencia $(38 \mathrm{~cm}$.) que posee abundante material arqueológico, conteniendo seguramente los restos de los niveles postpaleolíticos que ya se habían constatado en los proyectos anteriores. A continuación aparece un potente nivel $(78 \mathrm{~cm}$.), al parecer, Epipaleolítico -aunque de escasa extensión- excavado ampliamente en los años 60 por E. Ripoll $(1960,1961 / 62)$ y en 1975 por M. Botella y cuyo material fue estudiado posteriormente por A. Suárez (1981). Este horizonte cultural se conservaba presumiblemente sólo en esta zona del abrigo, habiendo desaparecido en el resto. El material aparece entre grandes bloques de piedras y el sedimento es muy suelto y polvoriento lo que en ocasiones le confiere un cierto aspecto de estar removido.

Debajo, sin una aparente discontinuidad, salvo por un ligero cambio de coloración del sedimento, se presenta el Nivel I de color amarillento, que es estéril, sin industria lítica, pero con algunos restos faunísticos de colonias naturales, fundamentalmente microfauna, lagomorfos y aves. Este estrato tiene un espesor de casi un metro $(93 \mathrm{~cm}$.) y posee gran cantidad de cantos angulosos procedentes de desprendimientos de la visera que además estan muy lavados debido a un alto grado de pluviosidad según demostró el análisis sedimentológico realizado por $\mathbf{J}$. Jordá Pardo y M.P. Carral (1988). Así mismo el nivel I de esta zona se paraleliza perfectamente con nuestro también nivel I encontrado en el centro del abrigo (Ripoll López et alii, 1988)

En la secuencia estratigráfica que estamos describiendo, seguidamente se encuentra nuestro nivel II, encuadrado en el Solutrense Superior Evolucionado, que en esta zona tiene poco espesor (oscila entre 12 y $18 \mathrm{cms}$.). Este nivel más reciente del Solutrense en La Cueva de Ambrosio posee una datación de $16500 \pm 280$ B.P. y una composición industrial del grupo solutrense con algunas hojas de laurel, abundantes puntas de aletas y pedúnculo y puntas de muesca de retoque abrupto y ausencia total de puntas de cara plana. El componente de hojitas de dorso adquiere una gran representatividad al igual que el de los buriles que casi siempre son diedros de ángulo (Ripoll López et alii, 1988).

El siguiente nivel (III), también estéril y de color amarillento, vuelve a tener las mismas características que las descritas en el Nivel I. Hay que destacar la existencia de algunos restos de talla, procedentes sin duda de la filtración del nivel superpuesto. En esta zona podemos diferenciar la parte superior con mayor número de cantos angulosos y la parte inferior compuesta por arenas. En la zona central del abrigo que nosotros hemos excavado, alcanza este estrato una potencia de $85 \mathrm{cms}$. En la parte oeste del abrigo, hemos llegado hasta la base del nivel, con una potencia de $70 \mathrm{~cm}$., que se asemeja mucho a la excavada anteriormente. Este nivel estéril (III) en la parte interior del abrigo, donde se sitúa el panel II, se convierte en una acumulación de arenas de transporte fluvial que en parte todavía cubre la representación pintada de la cabeza de caballo negra (núm. 10). Inmediatamente debajo de esta capa se encuentra un paquete sedimentario mucho más húmedo de lo que normalmente aparece en esta estación y que encuadramos con toda seguridad en el Solutrense Superior ya que se correspondería con el nivel IV excavado anteriormente por nosotros y datado en el $16620 \pm 280$ B.P. El conjunto industrial solutrense de este nivel esta compuesto por numerosas hojas de laurel, algunas

T. P., 51, n. $^{\circ} 2,1994$ 
puntas de cara plana, algunas puntas de muesca de retoque abrupto y de forma esporádica aparecen puntas de aletas y pedúnculo. Son muy raras las hojas de sauce y el grupo de las hojitas y los buriles pierden representatividad con respecto a la descripción que hemos hecho para el nivel II.

Todos estos niveles hasta aquí descritos, que juntos tienen una potencia de 2,97 metros, serían los que cubrirían el panel I tanto en su parte superior como inferior y el panel II. El panel III situado a la misma altura que el II únicamente estaría cubierto por el nivel II y III ya que la bóveda del abrigo en esta zona es muy baja.

Además de una posición cronológica perfectamente establecida por los niveles arqueológicos que como hemos visto cubrían estas representaciones, estilísticamente su adscripción cultural es muy próxima ya que casi todas ellas se incluirían en el estilo III del Prof. A. LeroiGourhan. Los motivos que nos llevan a clasificarlas dentro de este apartado es que la línea cérvico-dorsal de las figuras tiende a desvanecerse haciéndose muy tenue en el caso de la pintura y perdiéndose casi totalmente en el caso del grabado. La naturalidad que tienen todas las representaciones, alejándose de los elementos estereotipados que caracterizan al estilo II, así como algunas de las líneas de despiece de las crines de los équidos, junto con la ya mencionada desaparición de la curva cérvico-dorsal, nos hacen pensar que nos encontramos en un momento avanzado del estilo III propuesto por Leroi-Gourhan (1965). Así mismo los caballos barbados cuyo paralelismo con los hallados en la cueva de Les Combarelles (Eyzies, Francia) (Barrière, 1985) y cuyo encuadre solutrense ya fué asignado en su día, redunda en la idea de que estas representaciones se tienen que adscribir necesariamente a este período. De cualquier forma, si aceptamos la subdivisión estilística de este investigador francés, las representaciones de La Cueva de Ambrosio habría que situarlas en un momento final del Solutrense o tal vez en el inicio del Magdaleniense. Como ya hemos expuesto en otros trabajos este momento final del Solutrense se correspondería con el Solutrense Superior mientras que el Solutrense Superior Evolucionado sustituiría en esta zona levantina al Magdaleniense Inferior y Medio (Ripoll López, 1988).
En definitiva, la adscripción crono-cultural es la misma tanto desde el punto de vista arqueológico como estilístico.

En cuanto a la posible interpretación del conjunto pictórico de La Cueva de Ambrosio, podríamos caer en las ya manidas teorías de la magia propuestas por Salomon Reinach o Begouen y la del arte por el arte seguida fundamentalmente por Boule, entre otras. Sin embargo la mayoría de los autores contemporáneos prefieren conjugar ambas teorías. Esta diversidad de interpretaciones se corresponde con una realidad sumamente compleja y sería vano el buscar explicaciones de carácter general para una justa y correcta explicación del arte paleolítico.

Sin duda al analizar las representaciones prehistóricas podemos pensar que hay algo más y que los artistas no plasmaron este, cada día más amplio, repertorio de figuras simplemente para sentirse fuertes frente a las especies que iban a cazar, o bien como una simple zooteca. Pensamos que la constatación de la existencia de arte rupestre paleolítico en estaciones de carácter no permanente como La Cueva de Ambrosio, obliga a revisar las líneas de investigación seguidas hasta ahora y a contemplar el fenómeno artístico paleolítico en un contexto amplio que comprenda el marco geográfico regional y socioeconómico de las sociedades que lo desarrollaron. Sólo así pueden surgir nuevos planteamientos y cuestiones de interés en torno al siempre resbaladizo tema de la comprensión del arte paleolítico o su porqué. Aún así nosotros no queremos abordar de momento esta ardua cuestión de la interpretación, que creemos esconde un motivo intrínseco, aunque indescifrable para nosotros, en su realización. También pensamos que este delicado campo de la investigación sobre el papel que jugó el arte prehistórico, es limitado y la mayor parte nos es absolutamente desconocido y por ello las especulaciones interpretativas suelen llevar a resultados excesivamente simplistas. Es por todo ello que por ahora nos limitaremos a constatar que en las paredes del abrigo de La Cueva de Ambrosio existe una serie de figuras, fundamentalmente équidos, grabados y pintados.

En una región donde las manifestaciones pictóricas paleolíticas son muy escasas, cuando no ausentes, estas representaciones son sorprendentemente clásicas. La Cueva de Ambrosio es una de las pocas estaciones con arte rupestre parietal de la Península Ibérica datada de 
una manera absoluta, que además posee la característica de hallarse en la zona mediterránea, donde casi siempre se hace referencia a la colección de plaquetas de la cueva del Parpalló (Gandía, Valencia) (Pericot García, 1942; Villaverde Bonilla, 1994), así como de encontrarse las figuras al aire libre al tratarse de un abrigo y no en la profundidad de una cueva desprovistas de iluminación natural. Estas figuras parietales además de ofrecer un gran interés por su importancia y calidad artística, ciertamente superior a las que normalmente se presentan en los escasos conjuntos de arte rupestre paleolítico de la región mediterránea, lo tienen por su situación geográfica en el Sureste español. El descubrimiento de estas figuraciones viene a llenar el vacío que existía en esta zona en la dispersión geográfica del arte parietal cuaternario de la Península Ibérica, únicamente representado por el équido piqueteado de estilo paleolítico de Piedras Blancas (Escullar, Almería) (Martínez, 1986/87). Como ya hemos explicado en numerosas ocasiones, la Cueva de Ambrosio se encuentra situada en la cabecera del valle del arroyo del Moral siendo su posición geográfica de gran importancia ya que constituye el centro de una encrucijada de vías naturales para acceder desde el Levante mediterráneo al interior de Andalucía. Esta zona montañosa esta limitada al Norte por los extensos llanos que unen Caravaca de la Cruz, en la provincia de Murcia con La Puebla de Don Fadrique, Huescar y Baza ya en la provincia de Granada, donde se encuentra con la otra vía sureña de penetración. Se trata de las Ramblas de Nogalte y de Chirivel que unen Puerto Lumbreras, también en Murcia, con la población antes citada (Baza). La situación privilegiada en esta zona pudo contribuir a la difusión y síntesis de determinados tratamientos estéticos, estilísticos y temáticos, ya sea desde la Andalucía continental hacia el Levante o bien al contrario.

Hay que señalar que, cuando se pueda retirar totalmente los depósitos de piedra y sedimento intacto que cubrían, y en parte todavía cubren parte de estos paneles de la cueva, seguramente aparecerán nuevas figuras que engrosarán el inventario y será entonces cuando abordemos el estudio de posibles paralelos, es decir cuando la documentación y registro esté totalmente completo.

En Europa únicamente existen dos yacimientos paleolíticos que posean las característi- cas de posibilidad de datación absoluta por estar cubiertas las representaciones por niveles arqueológicos y se trata de la cueva de La Viña (Asturias), donde se encontraron algunas representaciones naturalistas cubiertas por niveles encuadrados en el Magdaleniense medio cantábrico evolucionado (Fortea, 1981 y 1990) y la grotte de La Tête du Lion en Francia (Ardeche, Francia) (Combier, 1972 y 1977) en la que las representaciones pictóricas no estaban propiamente cubiertas por los estratos, pero la excavación sistemática realizada en la base de las pinturas, proporcionó los útiles, "lápices" y carbones utilizados para su realización, que permitieron datarlas. A partir de ahora habrá que añadir el conjunto de figuraciones halladas en La Cueva de Ambrosio.

Los frecuentes descubrimientos de estaciones con arte prehistórico al aire libre o en yacimientos, como puede ser el caso que nos ocupa, sin duda introducirán numerosos e importantes cambios en las ideas generalmente admitidas referentes a la distribución geográfica, tanto del arte paleolítico como del llamado arte postpaleolítico. Los esquemas impuestos por grandes investigadores han provocado que estas zonas fueran tenidas como excepciones que contradecían objetivamente los pragmatismos al uso, de cómodo manejo y que incorporaban marginalmente, a lo sumo, a sucesivas puestas al día que, al poco tiempo, quedaban a su vez anticuadas al no modificar la base de los problemas, limitándose a aceptar supuestos anómalos que al multiplicarse, nos obligan a realizar una revisión de estos problemas, hasta ahora admitidos como indiscutibles. Estas cuestiones deberán de ser abordadas en profundidad en reuniones científicas específicas que aporten alguna luz a la distribución y datación del arte rupestre paleolítico peninsular.

\section{BIBLIOGRAFÍA}

BARRIERE, Cl. (1985): La grotte des Combarelles I. Releves des gravures de la galerie profonde. Travaux de l'Institut d'Art Préhistorique, XXVII. Université de Toulouse-Le Mirail, 79 pp.

CACHO, C. y Ripoll López, S. (1987): "Nuevas piezas de arte mueble en el Mediterráneo español". Trabajos de Prehistoria, 44: 35-62. Madrid.

Combier, J. (1972): "La Grotte de la Tête du Lion à Bidon (Ardèche)". Etudes Préhistoriques, 3, diciembre: $1-11,7$ figuras. Lyon.

T. P., 51, n. $^{\circ} 2,1994$ 
- (1977): "Dix ans de recherches préhistoriques dans la région Rhône-Alpes (1965-1975)". Gallia Préhistoire, 20, 2: 576-578, 1 fig. París.

FORTEA, J. (1981): "Investigaciones en la Cuenca Media del Nalón. Asturias (España)". Zephyrus, XXXII-XXXIII: 5-16. Salamanca.

Fortea, J.; Corchón, S.; González Morales, M.; Rodriguez Asensio, A.; Hoyos, M.; Laville, H.; DuPRE, M. Y FERnÁNDEZ-TREsGUERRES, J. (1990): "Travaux récents dans les vallées du Nalón et du Sella (Asturies)". Colloque International "L'art des objets au Paléolithique", I, L'art mobilier et son contexte (FoixLe Mas d'Azil, 1987): 219-244, 16 figs. París.

Jordá PARdo, J. y CARral, M.P. (1988): "Geología y estratigrafía del yacimiento prehistórico de la cueva de Ambrosio (Vélez-Blanco Almería)". En S. Ripoll López (ed.): La Cueva de Ambrosio (Vélez-Blanco, Almería) y su posición cronoestratigráfica en el Mediterráneo Occidental. British Archaeological Report, 462: 19-40. Oxford.

Leroi-Gourhan, A. (1965): "La Préhistoire de l'art occidental". Edit. Mazenod. París, 319 pp. con lams y cuadros.

Martinez Garcia, J. (1986/1987): "Un grabado paleolítico al aire libre en Piedras Blancas (Escullar, Almería)". Ars Praehistorica, V/VI: 49-58, 8 figs. Barcelona

Munsell (1954): soil color charts. Munsell Company Inc., Baltimore.

Pericot Garcia, L. (1942): La cueva del Parpalló (Gandía). Consejo Superior de Investigaciones Científicas, Instituto Diego Velázquez, Madrid, 349 pp., 650 figs. y XXXII lams.

Ripoll López, S. (1988): La Cueva de Ambrosio (VélezBlanco, Almería) y su posición cronoestratigráfica en el Mediterráneo Occidental. British Archaeological Report, 462, 2 vols., $596 \mathrm{pp}$., Oxford.

- (1989): "Le gisement de La Cueva de Ambrosio: Nouveaux Apports au Solutréen de la Péninsule Ibérique". L'Anthropologie, 92, 4: 851-886, 20 figs. París.

- (1990): "Le Solutréen dans le Sud de la Péninsule Ibérique". Colloque International sur "Les industries á pointes foliacées du Paléolithique Supérieur européen" (Instytut Archeologii Universytet Jagiellonski, Cracovia, 25 de Septiembre a 10 de Octubre de 1989). E.R.A.U.L., 42: 449-465, 8 figs. Liège.

- (1993): "Proyecto: Estudio Cultural, Reconstrucción paleoecológica y posición cronoestratigráfica del Pleistoceno Superior Final en la Andalucía Oriental. "La Cueva de Ambrosio (Vélez-Blanco, Almería)". Investigaciones Arqueológicas en Andalucía: Proyectos (Huelva, Enero de 1993): 239-251, 1 fig.

- (1994): "L'art rupestre paléolithique de La Cueva de Ambrosio (Almería, Espagne)". International Newsletter on Rock Art. Bulletin de l'I.N.O.R.A., 7: 1-2. Foix.

Ripoll López, S. y CACHO, C. (1990): "Art mobilier du Paléolithique mediterranéen espagnol: quelques nouvelles découvertes". Colloque International "L'art des objets au Paléolithique" (Foix-Le Mas d'Azil, Noviembre de 1987). L'Art del objets au Paléolithique: 287. 293, 2 figs. Ministère de la Culture. Foix.

Ripoll lópez, S.; Muñoz, F.J.; Ascasibar, J.; Calleja, F. y Gomis, E. (e.p.) "Arte Rupestre Paleolítico en el yacimiento de La Cueva de Ambrosio (Vélez-Blanco, Almería)". Primer Congrés Internacional de gravats rupestres y murals (Lleida, 23-27 de noviembre de 1992).

Sánchez MArco, A. (1988): "La Avifauna de La Cueva de Ambrosio". En S. Ripoll López (ed.): La Cueva de Ambrosio (Vélez-Blanco, Almería) y su posición cronoestratigráfica en el Mediterráneo Occidental. British Archaeological Report, 462: 143-156. Oxford.

Suárez Márouez, A. (1981): "Cueva de Ambrosio (Vélez-Blanco, Almería). Nuevas aportaciones al estudio del Epipaleolítico del Sudeste Peninsular". Arqueología y Paleoecología Humana, 2: 43-53. Granada.

Villaverde Bonilla, V. (1994): Arte Paleolítico de la Cova del Parpalló. Estudio de la colección de plaquetas y cantos grabados y pintados. Servei de Investigació Prehistòrica Diputació de València. Valencia, 2 tomos I: 404 pp., 50 figs. y LXXV lams.; II: inventario y 316 figs.

T. P., 51, n. $^{\circ} 2,1994$ 